\title{
MANOBRA DE EPLEY NA VERTIGEM POSICIONAL PAROXÍSTICA BENIGNA (VPPB) BILATERAL PÓS NEURITE VIRAL: RELATO DE CASO
}

\author{
Adirléia Machado ALVES ${ }^{1}$ \\ Cristiane Akemi KASSE ${ }^{2}$ \\ Flávia DONÁ ${ }^{3}$
}

\begin{abstract}
${ }^{1}$ Fisioterapeuta, especialista pela Universidade Estadual de Campinas (UNICAMP) e aluna do programa de Mestrado Profissional em Reabilitação do Equilíbrio Corporal e Inclusão Social da Universidade Anhanguera de São Paulo. a_malves@yahoo.com.br

${ }^{2}$ Otorrinolaringologista, doutora pela Universidade Federal de São Paulo (UNIFESP) e docente do programa de Mestrado Profissional em Reabilitação do Equilíbrio Corporal e Inclusão Social da Universidade Anhanguera de São Paulo.cris.kasse@gmail.com

${ }^{3}$ Fisioterapeuta, doutora pela Universidade Federal de São Paulo (UNIFESP) e docente do programa de Mestrado Profissional em Reabilitação do Equilíbrio Corporal e Inclusão Social da Universidade Anhanguera de São Paulo. flavia.dona@gmail.com
\end{abstract}

Corresponding author: Cristiane Akemi Kasse, MD, PhD.

Endereço: Rua Maria Cândida, 1.813, 02071-013, São Paulo - SP, Brazil. Programa de Mestrado em Reabilitação do Equilíbrio Corporal e Inclusão Social da Universidade Anhanguera de São Paulo. E-mail: cris.kasse@gmail.com.

\section{Recebido em: 30/05/2014 - Aprovado em: 15/09/2014 - Disponibilizado em: 15/12/2014}

RESUMO: A VPPB é considerada a vestibulopatia mais prevalente e a manobra de Epley é uma das opções para o tratamento dos canais verticais. O presente estudo teve como objetivo avaliar a efetividade da manobra de Epley no tratamento de um paciente com VPPB bilateral pós neurite viral. Paciente do sexo feminino, 69 anos, com histórico de tontura há mais de cinco anos, de instalação súbita, com desmaio, vômitos e quedas recorrentes. Há três meses, a vertigem e o desequilíbrio corporal vêm ocorrendo diariamente, apresentando piora após os movimentos de tronco e cabeça, associada à instabilidade postural e náusea. No exame clínico, o teste de Dix Hallpike, diagnosticou VPPB do tipo ductolitíase posterior bilateral. Os métodos de avaliação utilizados foram o Indice de Marcha Dinâmica (Dynamic Gait Index - DGI) e a posturografia computadorizada estática integrada à realidade virtual (Balance Reabilitation Unit$B R U^{\mathrm{TM}}$ ). Verificou-se a área de limite de estabilidade (LE), a área do centro de pressão (COP) e a velocidade (VOS) em diversas condições. Na reabilitação vestibular (RV), a manobra utilizada foi a de Epley em diferentes momentos, com intervalo de uma semana entre eles, até a melhora total. Após tratamento, houve aumento da pontuação no DGI (Pré: 16 pontos; Pós: 24 pontos), aumento da área do LE (Pré: $105 \mathrm{~cm}^{2}$; Pós: $158 \mathrm{~cm}^{2}$ ) e diminuição da oscilação corporal em todas as condições avaliadas. Desta forma, concluímos que a manobra de Epley foi efetiva no tratamento do paciente com VPPB bilateral pós neurite viral.

Palavras - Chave: Vertigem Posicional Paroxística Benigna. Ductolitíase. Neurite Viral. Manobra de Epley. Equilíbrio Corporal.

\section{EPLEY MANEUVER IN BENIGN PAROXYSMAL POSITIONAL VERTIGO (BPPV) BILATERAL POST VESTIBULAR NEURITIS: CASE REPORT}

\begin{abstract}
ABSTRAT: BPPV is considered the most prevalent vestibular disease and Epley's maneuver is one of options for treatment of vertical canal affection. The present study aimed to evaluate the effectiveness of the Epley maneuver in the treatment of a patient with bilateral BPPV post viral neuritis. Female patient, 69 years old, with a history of dizziness for more than five years, sudden onset, with fainting, vomiting and recurrent falls . Three months ago, vertigo and imbalance are occurring daily, worsen with the movements of the trunk and head, following by postural instability and nausea. The Dix Hallpike test for the posterior canal diagnosed the ductolithiasis Bilateral. The methods for evaluation were the Dynamic Gait Index (Dynamic Gait Index - DGI) and computerized static posturography integrated with virtual reality (Balance Rehabilitation, Unit- BRU TM). The area of stability limit (LE) and the area and the velocity of the center of the body pressure (VOS) under various conditions were verified. For vestibular rehabilitation (VR), the Epley's maneuver was done at different times, with a one week interval between them, even the total improve. After treatment there was an increase in DGI score (Pre: 16 points; Post : 54 points), the LE (Pre : $105 \mathrm{~cm}^{2}$, Post : $158 \mathrm{~cm}{ }^{2}$ ) and decreased of VOS in all conditions evaluated. Thus, we conclude that the Epley maneuver was effective in the treatment of patient with bilateral BPPV post viral neuritis.
\end{abstract}

Keywords: Benign Paroxysmal Positional Vertigo. Ductolithiasis. Viral neuritis. Epley maneuver. Body Balance. 


\section{INTRODUÇÃO}

Vertigem posicional paroxística benigna (VPPB) é considerada uma das patologias mais frequentes do sistema vestibular e se caracteriza pela presença de episódios recorrentes de vertigens, desencadeados por determinados movimentos da cabeça ou mudanças de posturas (FURMAN; CASS, 1999; HERDMAN; TUSA, 2002; MAIA; DINIZ; CARLESSE, 2001).

A fisiopatologia pode ser explicada pelo desprendimento de estatocônios da mácula utricular que podem ficar presos na cúpula, denominado cupulolitíase, ou circularem livremente na endolinfa nos ductos dos canais semicirculares, denominado ductolitíase (SCHUKNECHT, 1969; HALL; RUBY, 1979).

$\mathrm{Na}$ VPPB, o acometimento do canal semicircular posterior é o mais comum, podendo ocorrer o envolvimento labiríntico bilateral o qual caracteriza a VPPB bilateral.

A vertigem relatada pelos pacientes com VPPB é de curta duração e fortes intensidades desencadeadas por movimentos rápidos da cabeça, sendo mais frequentes ao se levantar da cama, deitar e virar na cama, olhar para o alto e olhar para baixo. Movimentos bruscos, na posição ortostática, podem levar a quedas (NORRÉ, 1995).

Os indivíduos, geralmente, conseguem identificar a posição que desencadeia a crise, passando a evitá-la constantemente, que gera alterações posturais que pioram o quadro e aumentam a incapacidade funcional. A tontura nem sempre é rotatória, e pode ser acompanhada por enjoos (HOLSTEIN; DUE; HOLST, 1990; GANANÇA; CAOVILLA; MUNHOZ, 1999).

O diagnóstico é dado pela história sugestiva associado a positividade da manobra de Dix-Hallpike. A manobra é positiva quando desencadeia vertigem e nistagmo no paciente. $\mathrm{O}$ nistagmo rotatório apresenta latência de quatro a cinco segundos e duração de trinta a quarenta segundos. Com a repetição da manobra a intensidade do nistagmo diminui, até sua ausência em torno da terceira ou quarta repetição (MAIA; DINIZ; CARLESSE， 2001; LEMPERT; GRESTY; BRONSTEIN 1995; HILTON; PINDER, 2003).

A neurite viral é considerada a segunda causa mais comum de vertigem e, geralmente, é atribuída a uma infecção viral do trato respiratório superior ou do trato gastrintestinal ou a um evento para infeccioso (HOTSON; BALOH, 1998; BALOH, 2003; HALMAGYI, 2005; HANLEY; DOWD; CONSIDINE, 2001).

O paciente apresenta vertigem rotacional severa de início agudo e prolongado, que piora com o movimento de cabeça e está associada ao nistagmo, ao desequilíbrio postural e à náusea. Os sintomas desaparecem em horas e o retorno do equilíbrio corporal normal ocorre em semanas (FETTER, 2002).

O diagnóstico diferencial da neurite viral é inclui outros casos de vertigem, uma história 
e um exame físico detalhado e um audiograma (FETTER, 2002).

Com o intuito de identificar alterações do equilíbrio corporal e risco de quedas, diagnosticar o sistema que está comprometido, para correta intervenção, foram desenvolvidas diversas escalas (MARINHO JUNIOR; CAVENAGHI; MARINO, 2011).

Dentre as mais utilizadas está o Dynamic Gait Index (DGI) que foi desenvolvido por Shumway-Cook et al. (1995) e adaptado para o Brasil por Castro et al. (2006). Esta escala tem o objetivo de avaliar e documentar a capacidade do paciente de modificar a marcha em resposta às mudanças de determinadas tarefas, em pacientes idosos com comprometimentos no equilíbrio.

A posturografia computadorizada estática integrada à realidade virtual (Balance Reabilitation Unit - BRUTM) avalia indivíduos com tontura e desequilíbrio corporal, medindo a oscilação corporal e o centro de pressão do corpo (COP), através de uma plataforma de força, que transformam as oscilações mecânicas do corpo em sinais elétricos que são analisados. Os parâmetros mensurados são: limite de estabilidade (LE), velocidade de oscilação corporal (VOC) e a área de deslocamento do centro de pressão do corpo (COP), associado a estímulos visuais projetados em óculos de realidade virtual (BRU®, 2006; GAZZOLA et al., 2009; HAGEMAN; LEIBOWITZ; BLANKE,
Como forma de tratamento e alívio dos sintomas e do equilíbrio corporal causados pela VPPB de canais verticais, a manobra de Epley tem sido um dos métodos de escolha mais utilizado por apresentar grande índice de melhora ou cura. Composta por uma série de movimentos da cabeça, a manobra de Epley proporciona a volta dos fragmentos de otólitos para o utrículo (WOODWORTH; GILLESPIE; LAMBERT, 2004).

Esta manobra foi proposta e descrita em 1992, modificada em 1993 por Herdman et al. e é indicada para os casos de VPPB por ductolitíase de canais verticais. Em uma revisão sistemática realizada por Burlamaqui et al. (2006), evidenciaram que a manobra de Epley na VPPB, além de ser eficaz, mantém os resultados por pelo menos três meses após sua utilização.

A VPPB acomete, principalmente, a população idosa. Vários estudos foram feitos para identificar a efetividade do tratamento que é baseado em manobras de reposição com intuito de estabelecer o funcionamento normal do labirinto (HELMINSK et al., 2011; KASSE et al., 2012).

\section{OBJETIVO}

Avaliar a efetividade da manobra de Epley no tratamento de uma paciente com VPPB bilateral pós neurite viral. 1995). 


\section{MÉTODOS}

Este estudo é do tipo longitudinal realizado no Laboratório de Estudo e Pesquisa em Reabilitação do Equilíbrio Corporal e Inclusão Social da Universidade Anhanguera de São Paulo/SP e foi conduzida dentro dos princípios éticos obedecendo a Resolução 466/12 do Conselho Nacional de Saúde e foi aprovado pelo comitê de ética da instituição $(219 / 11)$.

A paciente participou voluntariamente, concordou e assinou o termo de consentimento livre e esclarecido. $\mathrm{O}$ tratamento foi realizado em diferentes momentos, com intervalo de 1 semana entre as manobras, totalizando 3 sessões.

\section{APRESENTAÇÃO DO CASO}

\section{Anamnese e Diagnóstico}

Trata-se de uma paciente do sexo feminino, M.M.G., 69 anos, que apresentou a primeira crise com tontura, vertigem, vômito e desmaio, há mais de 30 anos. Desde então, tem realizado tratamento medicamentoso. Há três meses, a vertigem e o desequilíbrio corporal vêm ocorrendo diariamente, que piora após os movimentos de tronco e cabeça, associada à instabilidade postural e náusea.

Os sintomas apresentados pela paciente, relacionados à disfunção vestibular foram: tontura, cefaleia, sensação de desmaio, instabilidade postural, ansiedade, náusea, escurecimento da visão, perda auditiva, distúrbios do sono e oscilopsia.
No exame clínico, para auxílio no diagnóstico, foi realizado o teste de Dix Hallpike e a paciente apresentou positividade para ambos os lados quando submetida à manobra, diagnosticando a VPPB do tipo ductolitíase posterior bilateral com distúrbio de equilíbrio corporal.

\section{Avaliação do Equilíbrio Corporal}

Para a avaliação do equilíbrio corporal e da eficiência da reabilitação foram realizados o DGI e o BRU $^{\mathrm{TM}}$, por apresentarem grande confiabilidade.

Para a realização do DGI, a paciente recebeu instruções do fisioterapeuta para a realização da marcha nas seguintes situações: marcha em superfície plana, mudança de velocidade da marcha, marcha com movimentos horizontais (rotação) da cabeça, marcha com movimentos verticais da cabeça, marcha e giro sobre o próprio eixo corporal, passar por cima de obstáculo, contornar obstáculos, subir e descer degraus. A pontuação máxima é de 24 pontos e um escore de 19 ou menos prediz maior risco para quedas e menor desempenho na marcha (CASTRO; PERRACINI; GANANÇA, 2006).

No BRUTM, verificou-se a área de LE e do COP e a VOC nas seguintes condições: superfície firme e olhos abertos; superfície firme e olhos fechados; superfície instável e olhos fechados; estímulo sacádico em superfície firme; estímulos optocinéticos 
(barras para à direita) em superfície firme; estímulos optocinéticos (barras para à esquerda) em superfície firme; estímulos optocinéticos (barras para baixo) em superfície firme; estímulos optocinéticos (barras para cima) em superfície firme; interação visuovestibular (barras - horizontal) em superfície firme e interação visuovestibular (barras - vertical) em superfície firme.

\section{Método de Tratamento - Manobra de Epley}

Após ser avaliada, a paciente foi submetida à reabilitação vestibular (RV) por meio da realização da manobra de Epley, que consiste em deslocar as partículas de endolinfa, retida no canal semicircular posterior para o utrículo.

Este procedimento, descrito por Epley, decorreu da seguinte maneira: a paciente foi colocada sentada na ponta da maca com a cabeça rodada a $45^{\circ}$ para um dos lados. Em seguida, foi levada rapidamente para a posição supina, com a cabeça rodada e pendente para além da margem da maca e mantida por 20-30 segundos. Depois, a cabeça foi rodada $90^{\circ}$ para o outro lado e, assim, permaneceu por 20 segundos. A cabeça foi novamente rodada $90^{\circ}$ para o mesmo lado juntamente com a rotação do corpo de uma posição supina para decúbito lateral, mantida assim por mais 20 segundos. A paciente voltou à posição sentada, com os pés pendentes para além da margem da maca.
A RV foi realizada em três sessões, sendo que a manobra de Epley foi à conduta escolhida e utilizada isoladamente em todas as sessões.

\section{RESULTADOS E DISCUSSÃO}

Silveira et al. (2007) analisaram o prontuário de 2345 pacientes com diagnóstico de VPPB, destes, 252 (10,9\%) apresentavam a VPPB bilateral monocanal, com idade entre 39 e 81 anos e predomínio no sexo feminino $(63,5 \%)$. O comprometimento de canal posterior bilateral ocorreu em $9,9 \%$ dos casos de VPPB, como foi caso desta paciente, que após ter sido avaliada, diagnosticou-se a VPPB bilateral de canal posterior.

Em um estudo realizado por Korn et al. (2007) em 123 pacientes com VPPB unilateral por ductolitíase do canal posterior, contataram que a repetição de manobras de Epley em uma mesma sessão resulta em um menor número de sessões para abolir o nistagmo de posicionamento do que uma única manobra por sessão.

Assim, como em nosso estudo, em que a paciente M.M.G. foi submetida a cinco repetições da manobra de Epley na primeira sessão, três repetições na segunda e uma repetição na terceira sessão com melhora completa dos sintomas relatada pela própria paciente.

Marchiori et al. (2011) avaliaram 5 pacientes com VPPB. Após serem submetidas a manobra de Epley todas apresentaram o 
desaparecimento do nistagmo e da queixa de vertigem já na primeira manobra.

A análise da melhora dos sintomas da paciente M.M.G. pode ser observada na tabela 1.

Tabela 1 - Sintomas relacionados à disfunção vestibular pré e pós reabilitação vestibular por meio da manobra de Epley.

\begin{tabular}{lcc}
\hline Sintomas & Pré RV & Pós RV \\
\hline Tontura & + & - \\
Cefaléia & + & + \\
Sensação de desmaio & + & - \\
Instabilidade postural & + & - \\
Ansiedade & + & + \\
Náusea & + & + \\
Escurecimento da visão & + & - \\
Perda auditiva & + & + \\
Distúrbios do sono & + & + \\
Oscilopsia & + & - \\
\hline
\end{tabular}

Legenda: (+) presente, (-) ausente. $\mathrm{RV}$ - reabilitação vestibular

Ao ser submetida ao DGI antes da RV, a paciente MMG apresentou 16 pontos, o que determinava grande risco de queda. Lucareli (2005) realizou um estudo em idosos com disfunção vestibular periférica. Estes apresentaram pior desempenho em algumas tarefas de deambulação do DGI quando comparados aos indivíduos mais jovens, nas faixas etárias de até 39 anos e entre 40 a 59 anos, corroborando aos nossos resultados.

\section{Após RV a paciente M.M.G.} apresentou aumento no escore do DGI de 16 para 23 com diminuição do risco de queda e melhora no desempenho da marcha. A evolução da paciente no DGI pode ser observada na tabela 2 .

No BRUTM, verificou-se um aumento da área LE, que foi de $105 \mathrm{~cm}^{2}$ na avaliação pré RV-para $158 \mathrm{~cm}^{2}$ após a RV.
Na Tabela 3, descrevemos os valores da área COP obtido por meio do BRU ${ }^{\mathrm{TM}}$ antes e após a RV.

Tabela 2 - Pontuação no Dynamic Gait Index (DGI) pré e pós reabilitação vestibular por meio da manobra de Epley.

\begin{tabular}{lcc}
\hline CONDIÇÕES & Pré- RV & Pós-RV \\
\hline $\begin{array}{l}\text { 1-Marcha em superfície } \\
\text { plana }\end{array}$ & 2 & 3 \\
$\begin{array}{l}\text { 2-Mudança na velocidade } \\
\text { da marcha }\end{array}$ & 2 & 3 \\
$\begin{array}{l}\text { 3-Marcha com rotação } \\
\text { horizontal de cabça }\end{array}$ & 2 & 3 \\
$\begin{array}{l}\text { 4-Marcha com rotação } \\
\text { vertical de cabeça }\end{array}$ & 2 & 3 \\
$\begin{array}{l}\text { 5-Marcha e rotação } \\
\text { 6-Passar por cima de um } \\
\text { obstáculo }\end{array}$ & 2 & 3 \\
$\begin{array}{l}\text { 7-Andar ao redor do } \\
\text { obstáculo }\end{array}$ & 2 & 3 \\
8-Degraus & 2 & 3 \\
\hline TOTAL DE PONTOS & $\mathbf{1 6}$ & $\mathbf{2 3}$ \\
\hline
\end{tabular}

Legenda: RV - reabilitação do equilíbrio.

Tabela 3 - Área do centro de pressão (COP) pré e pós reabilitação vestibular por meio da Manobra de Epley

\begin{tabular}{lcc}
\hline \multirow{2}{*}{ CONDIÇÕES } & \multicolumn{2}{c}{ Área de Elipse (COP) } \\
& Pré-RV & Pós-RV \\
\hline SF, OA & $21,07 \mathrm{~cm} 2$ & $0,96 \mathrm{~cm} 2$ \\
SF, OF & $40,9 \mathrm{~cm} 2$ & $1,26 \mathrm{~cm} 2$ \\
SE OF & $37,87 \mathrm{~cm} 2$ & $1,30 \mathrm{~cm} 2$ \\
Sacádico, SF & $1,72 \mathrm{~cm} 2$ & $1,22 \mathrm{~cm} 2$ \\
OPT, Barras $\rightarrow$, SF & $18,57 \mathrm{~cm} 2$ & $0,30 \mathrm{~cm} 2$ \\
OPT, Barras $\leftarrow$, SF & $36,12 \mathrm{~cm} 2$ & $0,69 \mathrm{~cm} 2$ \\
OPT, Barras $\downarrow$, SF & $38,80 \mathrm{~cm} 2$ & $1,25 \mathrm{~cm} 2$ \\
OPT, Barras $\uparrow, S F$ & $60,94 \mathrm{~cm} 2$ & $0,66 \mathrm{~cm} 2$ \\
IVV, Circular, Barras & $14,53 \mathrm{~cm} 2$ & $3,89 \mathrm{~cm} 2$ \\
(direção horizontal), SF & & \\
$\begin{array}{l}\text { IVV, Circular, Barras } \\
\text { (direção vertical), SF }\end{array}$ & $1,35 \mathrm{~cm} 2$ & $5,05 \mathrm{~cm} 2$ \\
\hline
\end{tabular}

Legenda: SF - superfície firme; SE - superfície espuma; OA - olhos abertos; OF - olhos fechados; $\rightarrow$ (direita); $\leftarrow$ (esquerda); $\downarrow$ (para baixo); $\uparrow$ (para cima) e IVV - interação vestíbulo-visual. RV: reabilitação vestibular.

A partir dos resultados obtidos na posturografia é possível observar melhora do equilíbrio corporal e redução da área do COP 
em todas as condições avaliadas, isto é maior controle postural e menor risco de quedas.

Kasse et al. (2012), submeteram a manobra de Epley 33 pacientes idosos com diagnóstico de VPPB. O resultado da posturografia mostrou aumento significante na área do LE, quando comparado aos valores pré $\left(134,27 \pm 55.32 \mathrm{~cm}^{2}\right)$ e pós $(181.03 \pm 47.79$ $\left.\mathrm{cm}^{2}\right)$ manobra de Epley $(\mathrm{p}<0.07)$.

Neste caso apresentado, a paciente apresentou redução na intensidade da vertigem e melhora do equilíbrio postural estático e dinâmico logo nas primeiras sessões, com remissão da vertigem e do nistagmo de posicional já na terceira sessão.

Em uma pesquisa realizada por Ganança et al. (2007), 62 pacientes com VPPB associada à doença de Ménière foram submetidos à manobra de Epley. Os autores observaram remissão da vertigem em 71,0\% dos pacientes, redução em $27,4 \%$ e permaneceu inalterada em $1,6 \%$.

A partir da análise deste caso, podemos dizer que o DGI e o BRU ${ }^{\mathrm{TM}}$ podem ser considerados instrumentos de valor na avaliação, documentação e monitoração do tratamento de doenças vestibulares, especificamente na VPPB, assim como a manobra de Epley foi fator determinante para a melhora do equilíbrio corporal e remissão/redução dos sintomas vestibulares desta paciente com diagnóstico VPPB do tipo ductolitíase posterior bilateral.

\section{CONCLUSÃO}

A manobra de Epley foi efetiva no tratamento da paciente com VPPB bilateral pós neurite viral, a qual promoveu remissão da tontura, náusea, nistagmo posicional e melhora do equilíbrio corporal funcional e redução do risco de quedas.

\section{REFERÊNCIAS}

BALOH, R.W. Vestibular neuritis. The New England Journal of Medicine, Los Angelis, v.348, n.11. p.1027-1032, 2003.

BRU®. Unidade de Reabilitação do Equilíbrio. Manual do usuário. Versão 1.0.7. Versão do Software: 1.3.5.0. Uruguai, Medicaa: 2006; p.132.

BURLAMAQUI, J.C.; CAMPOS, C.A.H.; MESQUITA NETO, O. Manobra de Epley para Vertigem Postural Paroxística Benigna: revisão sistemática. Acta

Otorrinolaringologia: v. 24,

CASTRO, S.M; PERRACINI, M.R; GANANÇA, F.R. Versão brasileira do Dynamic Gait Index. Revista Brasileira de Otorrinolaringologia, São Paulo, v.72, n.6, p.817- 825, 2006.

EPLEY, J.M. The canalith repositioning procedure: for treatment of benign paroxysmal positional vertigo. 
Otolaryngology Head Neck Surgery: v. 107, n. 3, p. 399-404, 1992.

FETTER, M. Disfunções do Sistema Vestibular In: HERDMAN, S.J. Reabilitação Vestibular. $2^{\mathrm{a}}$ ed.São Paulo: Manole; 2002. cap.5, p. 91 - 101.

FURMAN, J.; CASS, S.P. Benign paroxysmal positional vertigo. The New England Journal of Medicine: v. 341, n. 21, p. 1590-1596, 1999.

GANANÇA, C.F.; CAOVILLA, H.H.; GAZZOLA, J.M.; GANANÇA, M.M.; GANANÇA, F.F. Manobra de Epley na vertigem posicional paroxística benigna associada à doença de Ménière. Revista Brasileira de Otorrinolaringologia, São Paulo, v.73, n.4, 2007.

GANANÇA, M.M.; CAOVILLA, H.H.; MUNHOZ, M.S.L.; SILVA, M.L.M.;

FRAZZA, M.M.; GANANÇA, F.F.; GANANÇA, C.F. As muitas faces da vertigem posicional. Atualidades em geriatria. São Paulo, v. 21, n. 4, p. 8-14, 1999.

GAZZOLA, J.M.; DONÁ, F.; GANANÇA, M.M.; SUAREZ, H.; GANANÇA, F.F.; CAOVILLA, H.H. Realidade virtual na avaliação e reabilitação dos distúrbios vestibulares. Acta ORL - Técnicas em
Otorrinolaringologia, São Paulo, v.27, n.1, p.22-27, 2009.

HAGEMAN, P.A.; LEIBOWITZ, J.M.; BLANKE, D. Age and gender effects on postural control measures. Archives of Physical Medicine and Rehabilitation: v.76, n.10, p.961-965, 1995.

HALL, S.F.; RUBY, R.R.; MCCLURE, J.A. The mechanics of benign paroxysmal vertigo. Journal of Otolaryngology: v. 8, n.2, p.151158, 1979.

HALMAGYI, G.M. Diagnosis and management of vertigo. Clinical Medicine: v.5, n.2, p.159-165, 2005.

HANLEY, K.; DOWD, T.O.; CONSIDINE, N. A systematic review of vertigo in primary care. British Journal of General Practice: v.469, n.51, p.666-671, 2001.

HELMINSKI, J.O.; ZEE, D,S,; JANSSEN, I.; HAIN, T.C. Effectiveness of particle repositioning maneuvers in the treatment of benign paroxysmal positional vertigo: a systematic review. Physical Therapy: v.90,n.5, p.663-678, 2010.

HERDMAN, S.; TUSA, R.J. Avaliação e tratamento dos pacientes com vertigem postural paroxística benigna. In: HERDMAN, S.J. Reabilitação vestibular. Barueri: Manole; 2002. cap.19, p. 447-71. 
HERDMAN, S.J.; TUSA, R.J.; ZEE, D.S.;

PROCTOR, L.R.; MATTOX, D.E. Single

treatment approaches to benign paroxysmal positional vertigo. Otolaryngology Head

Neck Surgery: v.119, n.4, p.450-454, 1993.

HILTON, M.; PINDER, D. The Epley (canalith repositioning) maneuvers for benign paroxysmal positional vertigo. In: The Cochrane Library.Oxford: Update Software; 2003.

HOLSTEIN, A.G.; DUE, P.; HOLST, E. Ego Informed Health Condition and Use of Drug Among the Old Man. Ugeskrift for laeger: 152 (6), p. 386-391, 1990.

HOTSON, J.R.; BALOH, R.W. Acute vestibular syndrome. New England Journal of Medicine, 339, p. 680-685, 1998.

KASSE, C.A.; SANTANA, G.G.; BRANCOBARREIRO, F.C.A.; SCHARLACH, R.C.; GAZZOLA, J.M.; GANANÇA, F.F.; DONÁ, F. Postural control in older patients with benign paroxysmal positional vertigo.

Otolaryngology-Head and Neck Surgery, 146, p. 890-815, 2012.

KORN, G.P.; DORIGUETO, R.S.; GANANCA, M.M.; CAOVILLA, H.H.

Epley's maneuver in the same session in benign positional paroxysmal vertigo. Revista Brasileira de Otorrinolaringologia, São Paulo, v.73, n.4, p.533,539, 2007.
LEMPERT, T.; GRESTY, M.; BRONSTEIN, A. Benign positional vertigo: recognition and treatment. British Medical Journal, 311(7003), p. 489-491, 1995.

LUCARELI, J.G.A. Avaliação da marcha em pacientes com disfunção vestibular periférica por meio do Dynamic Gait Index.

[Dissertação]. São Paulo: Universidade Bandeirante de São Paulo, 2005.

MAIA, R.; DINIZ, F.; CARLESSE, A. Tratamento da vertigem posicional paroxística benigna com manobras de reposição. Revista Brasileira de Otorrinolaringologia, São Paulo, v.67, n.5, p.612-616, 2001.

MARCHIORI, L.L.M.; MELO, J.J.;

ROMAGNOLI, C.R.; OLIVEIRA, T.B.

Manobra de epley na vertigem posicional paroxística benigna: relato de série de casos.

\section{Arquivos Internacionais de}

Otorrinolaringologia, São Paulo, v.15, n.2, p.151-155, 2011.

MARINHO JUNIOR, C.; CAVENAGHI, S.; MARINO, L.H.C. Escalas de mensuração e modalidades fisioterapêuticas na reabilitação de pacientes com equilíbrio deficitário.

Arquivos de Ciências da Saúde, São José do Rio Preto, v.18, n.1, p. 44-49, 2011.

n. 1, p. $38-45,2006$.

NORRÉ, M.E. Reliability of examination data in the diagnosis of benign paroxysmal 
positional vertigo. American Journal of

Otolaryngology, 16, p.806-810, 1995.

SCHUKNECHT, H.F. Cupulolithiasis. Arch

Otolaryngology, v.90, n.6, p.765-78, 1969.

SHUMWAY-COOK, A.; WOOLACOTT,

M.H. Control of posture and balance. In:

Shumway-Cook A, Woolacott MH. Motor

Control Theory and Practical Applications.

Maryland: Williams \& Wilkins; 1995. p. 120.

SILVEIRA, S.M.R.M.; GANANÇA, C.F.

GANANÇA, M.M.; CAOVILLA, H.H..

Vertigem posicional paroxística benigna

bilateral monocanal. Acta ORL-Técnicas em

Otorrinolaringologia, São Paulo, v. 25, n.2, p.124-127, 2007.

WOODWORTH, B.A.; GILLESPIE, M.B.;

LAMBERT, P.R. The canalith repositioning

procedure for benign positional vertigo: a

meta-analysis. Laryngoscope, v.114, n.7, p.

1143 - 1146, 2004. 